\title{
Low-Temperature Plasma: An Effective Approach Against Candida albicans Biofilm
}

\author{
Juliana Aparecida Delben, ${ }^{\mathrm{a}, \mathrm{b}}$ Ramiro Mendonça Murata, ${ }^{\mathrm{b}}$ Xi Wei, ${ }^{\mathrm{b}}$ \\ Myrella Lessio Castro, ${ }^{b}$ Wirley Gonçalves Assunção, ${ }^{a}$ \\ Nelson Renato França Alves da Silva, ${ }^{c}$ \& Simone Duarte ${ }^{\mathrm{b}, *}$ \\ aDepartment of Dental Materials and Prosthodontics, Araçatuba Dental School, Sao Paulo State \\ University, Sao Paulo, SP, Brazil;'bepartment of Basic Science and Craniofacial Biology, New \\ York University College of Dentistry, New York, New York; 'Department of Biomaterials and Bio- \\ mimetics, New York University College of Dentistry, New York, New York
}

*Address all correspondence to: Simone Duarte, New York University College of Dentistry, 345 East 24th Street,
New York, NY 10010; Tel.: +1 (212) 998-9572; Fax: +1 (212) 995-4087; sd84@nyu.edu

\begin{abstract}
This study evaluated the antifungal potential of low-temperature plasma (LTP) on a 72-hour Candida albicans biofilm. A growth inhibition zone test was conducted with agar plates inoculated with C. albicans and submitted to LTP and argon application at 3 and $10 \mathrm{~mm}$ for 10 , $30,60,90$, and 120 seconds. The groups for biofilm assays were 60 seconds of LTP application with a tip-to-sample distance of $3 \mathrm{~mm}$ (LTP-3) and $10 \mathrm{~mm}$ (LTP-10); -application of only argon gas for 60 seconds with a tip-to-sample distance of $3 \mathrm{~mm}(\mathrm{Ar}-3)$ and $10 \mathrm{~mm}(\mathrm{Ar}-10)$; and no treatment. The $C$. albicans biofilm was grown on saliva-coated discs. The medium was replaced every 24 hours. Confocal laser scanning microscopy revealed the proportion of live and dead cells, and variable pressure scanning electron microscopy (VPSEM) showed biofilm/cell structure. No inhibition zone was observed for control and either Ar groups. For the LTP groups, a progressively increasing of inhibition zone diameter was observed for different treatment durations. The LTP-3 and LTP-10 groups presented higher proportions of dead cells compared with the Ar-3 and Ar-10 groups. VPSEM revealed cell perforations in the LTP-3 and LTP-10 groups. A short period of LTP exposure demonstrated an antifungal effect on C. albicans biofilm.
\end{abstract}

KEY WORDS: low-temperature plasma, oral biofilm, Candida albicans

\section{INTRODUCTION}

Oral candidosis is a common oral infection caused by Candida albicans ${ }^{1-3}$ and occurs in $10-75 \%$ of denture wearers. ${ }^{4-6}$ A major virulent attribute of C. albicans is its ability to adhere to a surface and form communities known as biofilms. ${ }^{7-9}$ Considering that cells within biofilms are protected from adverse environmental and host defense mechanisms, in comparison to planktonic cells, any method of microbial decontamination should be evaluated against a microbial biofilm structure. ${ }^{10}$

In dental prostheses the mucosa and fitting surfaces of complete dentures act as main reservoirs for yeasts. ${ }^{11-13}$ In addition, $C$. albicans in the oral cavity might lead to systemic infections, which are difficult to treat and have been linked to several cases of mortality $(40 \%){ }^{14}$

Currently, products containing peroxides, hypochlorites, and chlorhexidine diglu- 
conates are recommended for denture cleaning to remove $C$. albicans. Discoloring by oxygenating agents or black staining, ${ }^{2}$ however, have been considered some of the major side effects of its routine use. Therefore new approaches against $C$. albicans biofilms should be developed without damaging the living tissue and denture material.

Low-temperature plasma (LTP) is emerging as a physical treatment ${ }^{15}$ with microbicidal effectiveness on bacteria, parasites, fungi, spores, and viruses. ${ }^{16-18}$ Plasma is a partially ionized gas generated by an electrical discharge, which creates a highly reactive environment with ions, electrons, excited atoms and molecules, vacuum ultraviolet and ultraviolet (UV) irradiation, free radicals, and chemically reactive particles. ${ }^{2,19}$ The production of stable plasma at atmospheric pressure has attracted attention for treating living cells and tissues without thermal damage..$^{20,21}$ It is also site specific, targeting only the infected area, ${ }^{22}$ and it seems to preserve the material's bulk properties. ${ }^{19,23-25}$ In addition, plasma is usually produced by low-toxicity gases and elaborates its activity by producing a mixture of products that decay within a few seconds after the treatment process. Therefore, this approach has been suggested as environmentally friendly with no harmful residues. ${ }^{10}$

This study aimed to evaluate the antifungal potential of LTP on a 72-hour C. albicans biofilm grown on polymethyl methacrylate discs. The research hypothesis assumed that LTP application has antifungal activity on C. albicans biofilm, regardless of the distance between the LTP tip and the sample.

\section{MATERIALS AND METHODS}

\section{A. Experimental Design}

A 72-hour C. albicans (strain SC5314) biofilm was grown on polymethyl methacrylate (PMMA) resin discs covered by human saliva. The 72-hour biofilm assay was established based on a previous evaluation of biofilm development in variable-pressure scanning electron microscopy (VPSEM) (EVO-50; Carl Zeiss, Germany) from 24 to 96 hours (data not shown). According to this analysis, a dense polysaccharide matrix was progressively generated on the surface of the disc for up to 72 hours. After 96 hours, however, yeast cells started to detach from the polysaccharide matrix because of the biofilm characteristic of the cells' dissemination. After biofilm formation, the samples were randomly divided into 5 groups (Table 1).

\section{B. Specimen Preparation}

PMMA (ProBase Cold Resin; Ivoclar Vivadent, Canada) discs, $9 \mathrm{~mm}$ in diameter and 2 $\mathrm{mm}$ thick, were fabricated according to the manufacturer's instructions. The specimens then were stored in distilled water at $37^{\circ} \mathrm{C}$ for 7 days for residual monomer release $e^{26,27}$ and were ground using progressively smoother sandpaper (400-, 600-, 800-, and 1200grit) (Buehler, Germany). 
TABLE 1: Groups and Treatment Conditions

\begin{tabular}{llll}
\hline Group & Treatment & $\begin{array}{l}\text { Tip-to-Sample } \\
\text { Distance* }(\mathbf{m m})\end{array}$ & $\begin{array}{l}\text { Treatment Dura- } \\
\text { tion (seconds) }\end{array}$ \\
\hline Control & No treatment & - & - \\
Ar-3 & Argon gas application & 3 & 60 \\
Ar-10 & Argon gas application & 10 & 60 \\
LTP-3 & LTP application & 3 & 60 \\
LTP-10 & LTP application & 10 & 60 \\
\hline
\end{tabular}

*Tip-to-sample distance represents the distance between the sample and the device used for argon and argon-low-temperature plasma (LTP) application.

The surface roughness $(\mathrm{Ra})$ of the specimens was subsequently measured using an interferometer (AXIO Imager M1m; Carl Zeiss). Three readings were made for each specimen and the Ra was standardized at $0.34 \pm 0.02 \mu \mathrm{m} .{ }^{1}$

After the Ra was measured, the specimens were ultrasonically cleaned (Ultrasonic Cleaner FS140; Fisher Scientific) in ultrapure water (MilliQ system; Millipore, Billerica, MA) for 20 minutes to remove any contaminants and artifacts from the surfaces. ${ }^{28}$ Then, the samples were submitted to a single dose of 25.2-kGy gamma radiation (Gammacell 1000 Elite; Best Theratronics, Canada) for sterilization.

\section{Biofilm Assay}

A loopful of stock yeast culture of C. albicans (strain SC5314) was reactivated from its original culture in a Sabouraud dextrose agar plate (Becton, Dickinson and Co., Franklin Lakes, NJ) for 24 hours at $37^{\circ} \mathrm{C}$.

Five colonies of $C$. albicans were resuspended in $10 \mathrm{~mL}$ of culture medium containing Yeast Nitrogen Base (Becton, Dickinson and Co.) supplemented with $50 \mathrm{mmol} / \mathrm{L}$ dextrose (Fisher Scientific). The suspension was cultured overnight at $37^{\circ} \mathrm{C}$ and $5 \%$ carbon dioxide $\left(\mathrm{CO}_{2}\right)$ and used to prepare the inoculum at a 1:100 ratio of yeast suspension and culture medium.

The biofilm was formed on saliva-coated PMMA discs through incubation with clarified human whole saliva for 1 hour at $37^{\circ} \mathrm{C}$ in a 3-dimensional rotator (LabLine; Thermo Scientific). The human saliva was collected from a healthy donor by stimulation with flexible film (Parafilm M; Pechiney Laboratory Safety Products \& Apparel) in an ice-chilled polypropylene tube. Because no identifying information about the donor was collected, this research does not meet the definition of human subjects 45 CFR 46.102(f) and does not require institutional review board oversight. Adsorption buffer $(50 \mathrm{mmol} / \mathrm{L}$ potassium chloride, $1.0 \mathrm{mmol} / \mathrm{L}$ potassium phosphate, $1.0 \mathrm{mmol} / \mathrm{L}$ calcium chloride, 0.1 $\mathrm{mmol} / \mathrm{L}$ magnesium chloride; $\mathrm{pH} 6.5 ; 1: 1)$, as well as phenylmethylsulfonyl fluoride 
(PMSF; 1:1000), were added to the saliva. The solution was clarified by centrifugation at $8500 \mathrm{rpm}$ for 10 minutes at $4^{\circ} \mathrm{C}$, filtered using a filter with a $0.22-\mu \mathrm{m}$ pore size (Stericup; Millipore), and immediately used.

The saliva-coated discs were washed 3 times in sterile adsorption buffer, transferred to a new 24-well polystyrene cell culture plate (Becton, Dickinson and Co.), covered by $2 \mathrm{~mL}$ of the yeast suspension, and incubated at $37^{\circ} \mathrm{C}$ and $5 \% \mathrm{CO}_{2}$. The medium was changed every 24 hours up to 72 hours before treatment was accomplished. The procedure was performed in triplicate on 3 independent occasions.

\section{LTP Treatment}

An atmospheric-pressure LTP jet (Kinpen) developed by the Leibniz Institute for Plasma Science and Technology (Greifswald, Germany) was used for plasma treatment. The device consists of a hand-held unit (length $=170 \mathrm{~mm}$, diameter $=20 \mathrm{~mm}$, weight $=170$ g) that generates a plasma jet at atmospheric pressure, a direct current power supply (system power: $8 \mathrm{~W}$ at $220 \mathrm{~V}, 50 / 60 \mathrm{~Hz}$ ), and a gas supply unit. A pin-type electrode (1$\mathrm{mm}$ diameter) is mounted at the center of a quartz or ceramic capillary (inner diameter $=1.6 \mathrm{~mm})$. In the continuous working mode, a high-frequency voltage $(1.82 \mathrm{MHz}, 2-6$ $\mathrm{kVpp}$ ) is coupled to the pin-type electrode. The plasma is generated from the top of the electrode and expands to the surrounding air outside the nozzle ${ }^{2}$ (Fig. 1).

The system works with all rare gases at gas flow rates ranging between 5 and 10 slm (standard liters per minute). In this study the device worked with argon (Ar) gas at a 5-slm flow rate. The temperature was measured with a thermometer for 2 minutes and resulted in $30.67 \pm 0.58^{\circ} \mathrm{C}$ at a $3-\mathrm{mm}$ distance from the plasma tip and $29.83 \pm 0.29^{\circ} \mathrm{C}$ at

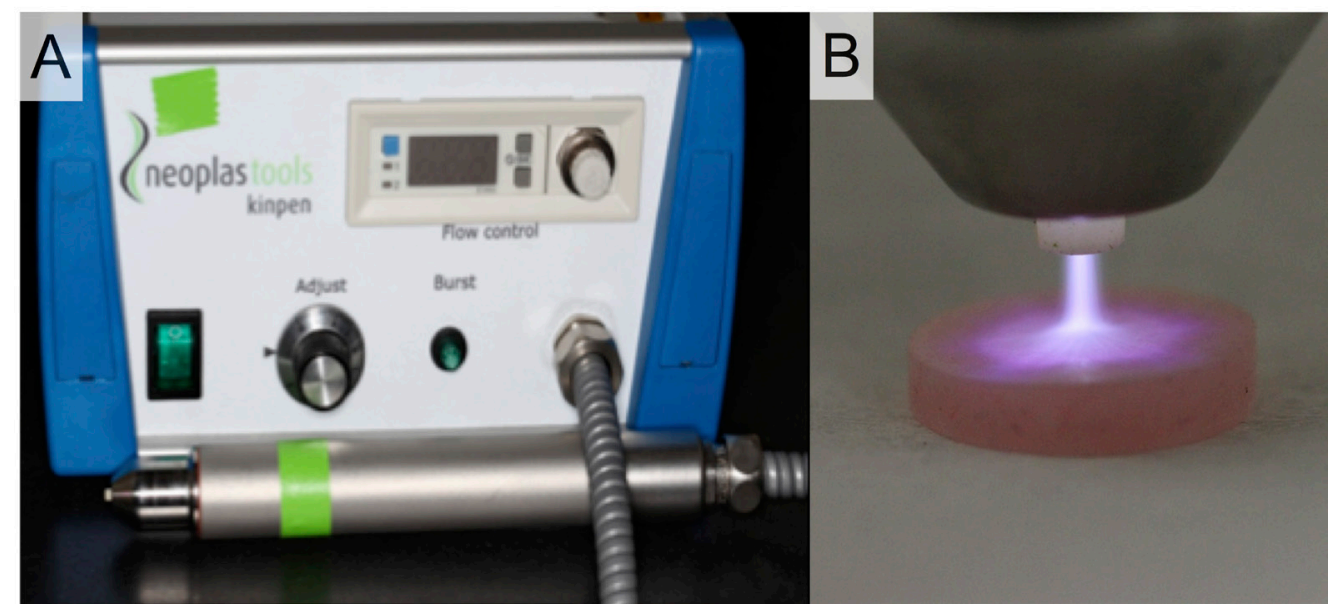

FIG. 1: (a) Kinpen plasma unit. (b) Low-temperature plasma application on a polymethyl methacrylate sample 
$10 \mathrm{~mm}$. The Ar gas flow/LTP plume was targeted to the center of the disc, and the tip-tosample distance (3 or $10 \mathrm{~mm}$ ) was kept constant during application using a fixed holder.

\section{E. Growth Inhibition Zone}

After reactivation of $C$. albicans (strain ATCC SC5314) culture, 5 colonies were resuspended in $10 \mathrm{~mL}$ of Yeast Nitrogen Base (Becton, Dickinson and Co.) supplemented with $50 \mathrm{mmol} / \mathrm{L}$ dextrose (Fisher Scientific) and cultured overnight at $37^{\circ} \mathrm{C}$ and $5 \%$ $\mathrm{CO}_{2}$. An inoculum of yeast suspension at a 1:20 ratio was inoculated in culture medium and incubated at $37^{\circ} \mathrm{C}$ and $5 \% \mathrm{CO}_{2}$ for 8 hours. The incubation time was calculated to reach the exponential growth phase.

The cells were washed 3 times with sterile $1 \%$ phosphate-buffered solution ( $\mathrm{pH} 7.4$ ) (Invitrogen) by centrifugation at $8500 \mathrm{rpm}$ for 10 minutes at $4{ }^{\circ} \mathrm{C}$ and standardized to 1 $\times 10^{7}$ cells $/ \mathrm{mL}$, which was ascertained through a spectrophotometer (Genesys 6 spectrophotometer; Thermo Scientific) at an absorbance of about 0.209 at $660 \mathrm{~nm}$.

Then, $50 \mu \mathrm{L}$ of the $C$. albicans suspension was spread on Sabouraud dextrose agar (Becton, Dickinson and Co.) plates and pure Ar gas (Ar groups) or plasma (LTP groups) was applied. Both treatments were conducted at different tip-to-plate distances (3 and $10 \mathrm{~mm}$ ) and for different durations (15, 30, 60, 90, and 120 seconds). A negative control group with no treatment also was evaluated. After treatment, the plates were incubated at $37^{\circ} \mathrm{C}$ and $5 \% \mathrm{CO}_{2}$ for 24 hours Then, the diameter of the growth inhibition zone was measured with a digital caliper. The procedure was performed in triplicate in 3 independent occasions.

\section{F. Confocal Laser Scanning Microscopy}

The Live/Dead BacLight bacterial viability kit (Molecular Probes; Invitrogen) was used to reveal the proportion of live or active cells (fluorescent green) and dead or inactive cells (fluorescent red). The live/dead stain was prepared by diluting $1.5 \mu \mathrm{L}$ of staining component A (SYTO 9) and $1.5 \mu \mathrm{L}$ of staining component B (propidium iodide) in 1 $\mathrm{mL}$ of sterile $1 \%$ phosphate buffered solution ( $\mathrm{pH}$ 7.4) (Invitrogen, USA). Each sample was covered with $1 \mathrm{~mL}$ of the reagent mixture and incubated for 15 minutes at room temperature, protected from light exposure. Fluorescence was captured with a Leica TCS SP5 II confocal microscope (Leica, Germany) with the objective Leica HCX APO L 40x/0.8 W U-V-I water dipping lens.

\section{G. Variable Pressure Scanning Electron Microscopy}

VPSEM was used in this study because it allows morphological analysis of the treated mature biofilms with no further preparation. The VPSEM (EVO 50; Carl Zeiss) in com- 
bination with the software SmartSEM (Carl Zeiss) was used for analysis. The images were captured at an extra high tension (EHT) of $15 \mathrm{Kv}$, probe current of $300 \mathrm{pA}$, vacuum of $100 \mathrm{~Pa}$, and a working distance of $10.5 \mathrm{~mm}$.

\section{RESULTS}

\section{A. Growth Inhibition Zone}

No growth inhibition zone was observed for either the negative control group or those cultures submitted to Ar gas application under all conditions (15, 30, 60, 90, and 120 seconds' duration/3 and $10 \mathrm{~mm}$ distance) (Fig. 2).

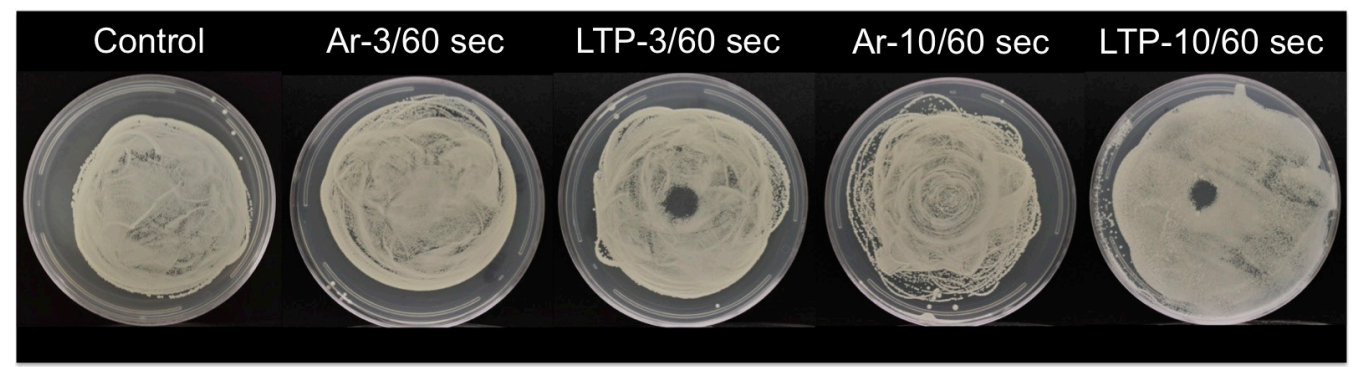

FIG. 2: Candida albicans culture in Sabouraud dextrose agar. A growth inhibition zone was observed for groups treated with low-temperature plasma (LTP). Ar, argon. Ar-3, argon gas application for 60 seconds with a tip-to-sample distance of $3 \mathrm{~mm}$; Ar-10, argon gas application for 60 seconds with a tip-to-sample distance of $10 \mathrm{~mm}$; LTP-3, 60 seconds of LTP application with a tip-to-sample distance of $3 \mathrm{~mm}$; LTP-10, 60 seconds of LTP application with a tip-to-sample distance of $10 \mathrm{~mm}$

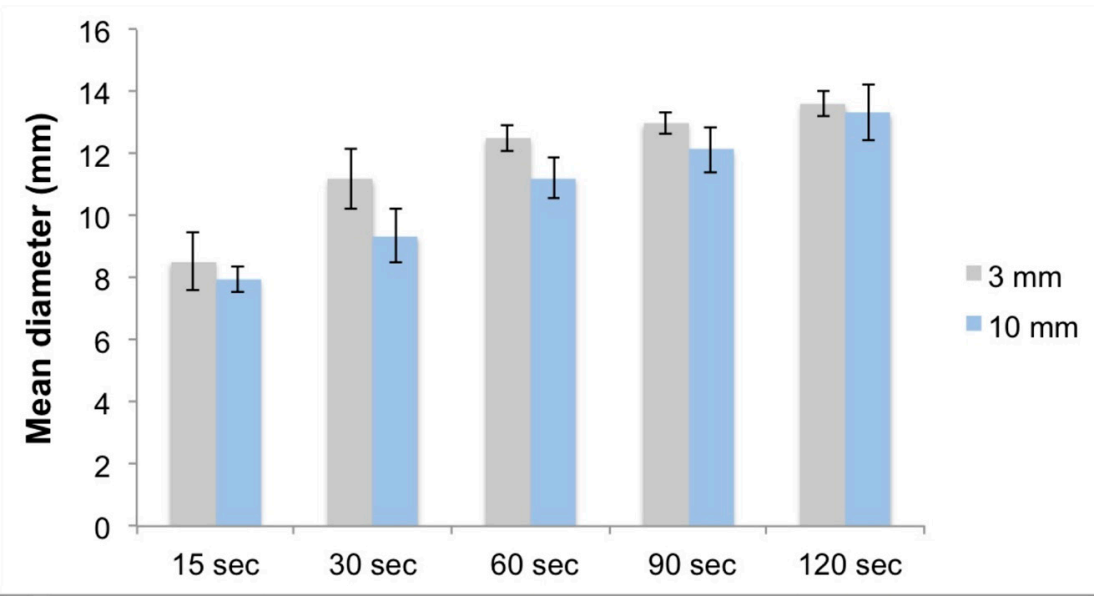

FIG. 3: Mean diameter (millimeters) of the growth inhibition zone exhibited for plasma application 
For those cultures submitted to LTP treatment, the longer the treatment, the wider the growth inhibition zone at both tip-to-sample distances (3 and $10 \mathrm{~mm}$ ). In addition, wider growth inhibition zones were observed when LTP application was conducted at a tip-to-sample distance of $3 \mathrm{~mm}$ compared with $10 \mathrm{~mm}$ for all treatment durations (Fig. 3).

\section{B. Confocal Laser Scanning Microscopy}

Figures 4 and 5 shows the proportion of live/dead cells in each group at $2 \times$ and $10 \times$, respectively. Figure 4 visually shows a larger amount of dead cells in the LTP groups compared with the control and Ar groups, whereas Fig. 5 reveals morphological alterations of the yeasts in the LTP groups.

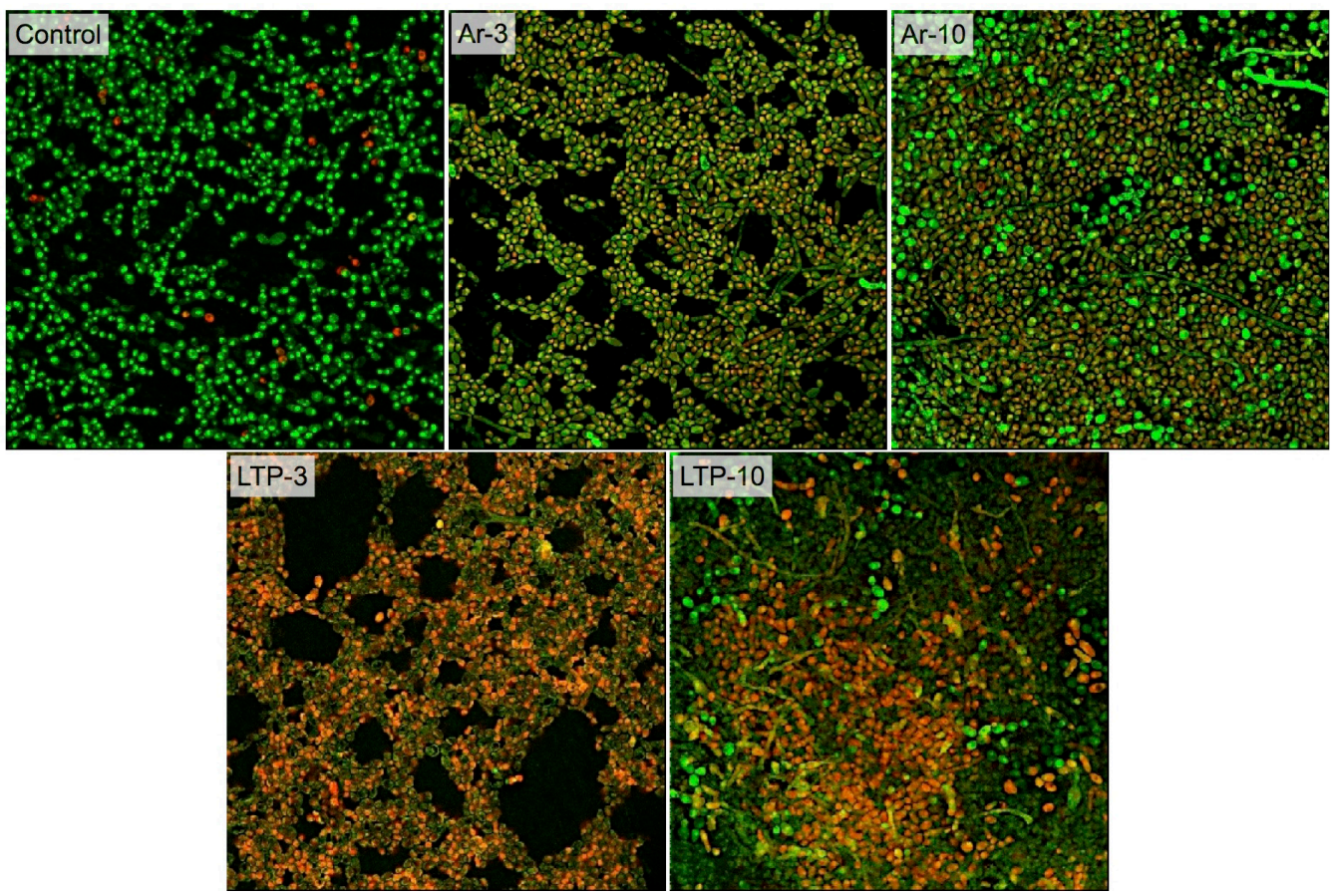

FIG. 4: Comparative analysis of Candida albicans biofilm in each group at 2×. Ar-3, argon gas application for 60 seconds with a tip-to-sample distance of $3 \mathrm{~mm}$; Ar-10, argon gas application for 60 seconds with a tip-to-sample distance of $10 \mathrm{~mm}$; LTP-3, 60 seconds of LTP application with a tip-to-sample distance of $3 \mathrm{~mm}$; LTP-10, 60 seconds of LTP application with a tip-to-sample distance of $10 \mathrm{~mm}$ 


\section{Variable Pressure Scanning Electron Microscopy}

The VPSEM images revealed cell perforations for the biofilm treated with LTP at both tip-to-sample distances (groups LTP-3 and LTP-10). On the other hand, no morphological alteration was observed for the biofilm of the negative control group (control group) and those submitted to only Ar gas application (groups Ar-3 and Ar-10) (Figs. 6 and 7).

\section{DISCUSSION}

According to the results of this study, the research hypothesis was accepted because LTP exhibited antifungal activity on C. albicans biofilm for both tip-to-sample distances.

The growth inhibition zone observed only on LTP-treated samples demonstrated that the activity against planktonic cells was promoted by plasma activation and not

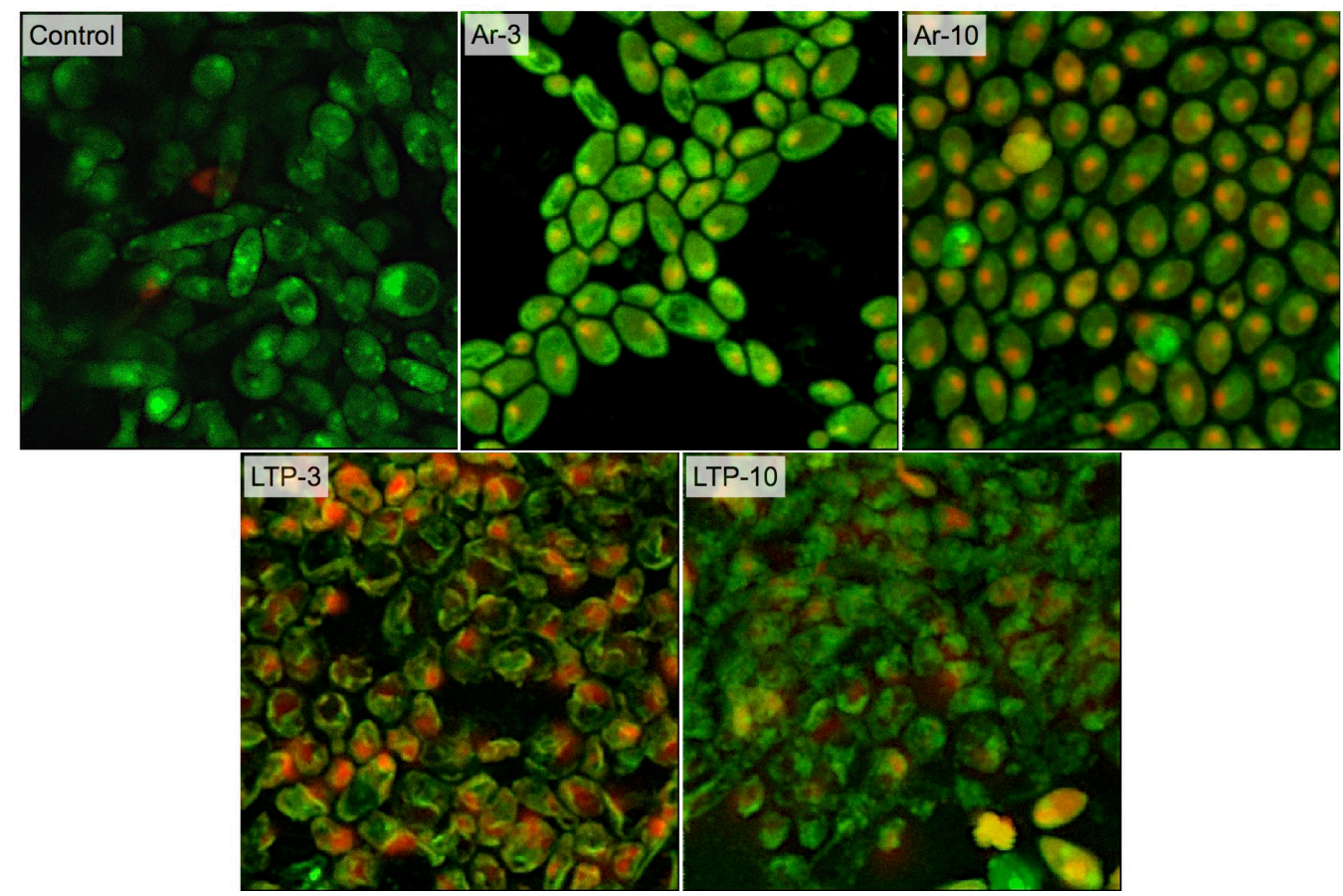

FIG. 5: Comparative analysis of Candida albicans biofilm in each group at 10×. Ar-3, argon gas application for 60 seconds with a tip-to-sample distance of $3 \mathrm{~mm}$; Ar-10, argon gas application for 60 seconds with a tip-to-sample distance of $10 \mathrm{~mm}$; LTP-3, 60 seconds of LTP application with a tip-to-sample distance of $3 \mathrm{~mm}$; LTP-10, 60 seconds of LTP application with a tip-to-sample distance of $10 \mathrm{~mm}$ 
by Ar gas flow. Data in the literature also show the effect of plasma on the inactivation of planktonic bacteria, yeasts, and spores..$^{29-31}$ Similar to another study, ${ }^{10}$ the measured inhibition zone diameters yield important information on the effective coverage area of
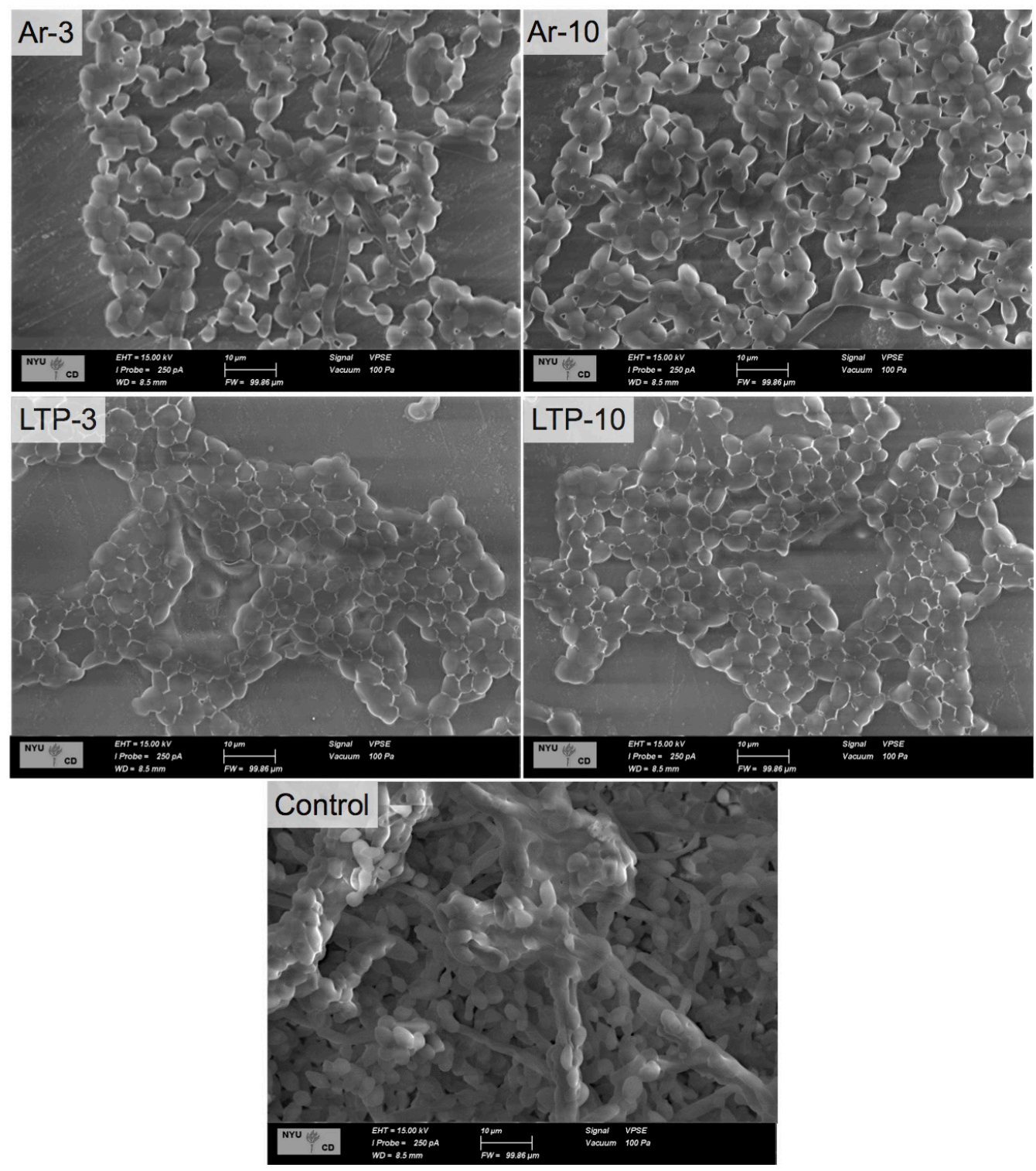

FIG. 6: Variable pressure scanning electron microscopyof samples of all groups. Ar-3, argon gas application for 60 seconds with a tip-to-sample distance of $3 \mathrm{~mm}$; Ar-10, argon gas application for 60 seconds with a tip-to-sample distance of $10 \mathrm{~mm}$; LTP-3, 60 seconds of LTP application with a tip-to-sample distance of $3 \mathrm{~mm}$; LTP-10, 60 seconds of LTP application with a tip-to-sample distance of $10 \mathrm{~mm}$ 
the active species generated by the plasma, which extended beyond the visible plasma plume.

Although the clear growth inhibition zone demonstrated the effect of plasma on planktonic cells, it has been repeatedly confirmed that $C$. albicans biofilms are more resistant to antifungal agents than planktonic structures (free-floating, nonadherent cells). ${ }^{10,32}$ The extracellular polysaccharides secreted by $C$. albicans after adhesion to dentures are the basis for the biofilm matrix, which protects the cells from different physical and chemical environmental influences. ${ }^{2}$

The results of confocal laser scanning microscopy confirmed the antifungal effect of LTP on C. albicans biofilm; the plasma-treated samples (groups LTP-3 and LTP-10) exhibited a larger amount of dead cells than the negative control group and those samples submitted to only Ar gas application (groups Ar-3 and Ar-10). Koban et al. ${ }^{2}$ also demonstrated the sterilization promoted by LTP on C. albicans biofilm. However, their results corresponded to a 48-hour biofilm on titanium discs, and the treatment was longer (1-10 minutes), which could be inappropriate for clinical routine. Furthermore, in the present study, LTP showed an antimicrobial effect against a mature $C$. albicans biofilm in a short exposure period (60 seconds). Similar to another study, ${ }^{33}$ confocal microscopy also revealed dead cells in those samples submitted to only Ar gas application. Although this result could suggest a certain antimicrobial effect of irrigation with noninert gase $\mathrm{s}^{34}$ even without plasma activation, dead microorganisms within a biofilm model grown under stationary conditions have been shown previously. ${ }^{35}$

The inactivation of biological agents promoted by LTP may result from deconstruction of the microorganism's genetic material (DNA) by UV radiation produced with plasma and erosion of the microorganisms through intrinsic photodesorption. The photon-induced desorption results from damage of chemical bonds in the microorganism after exposure to UV radiation, allowing its atoms to form volatile compounds. ${ }^{23,36}$

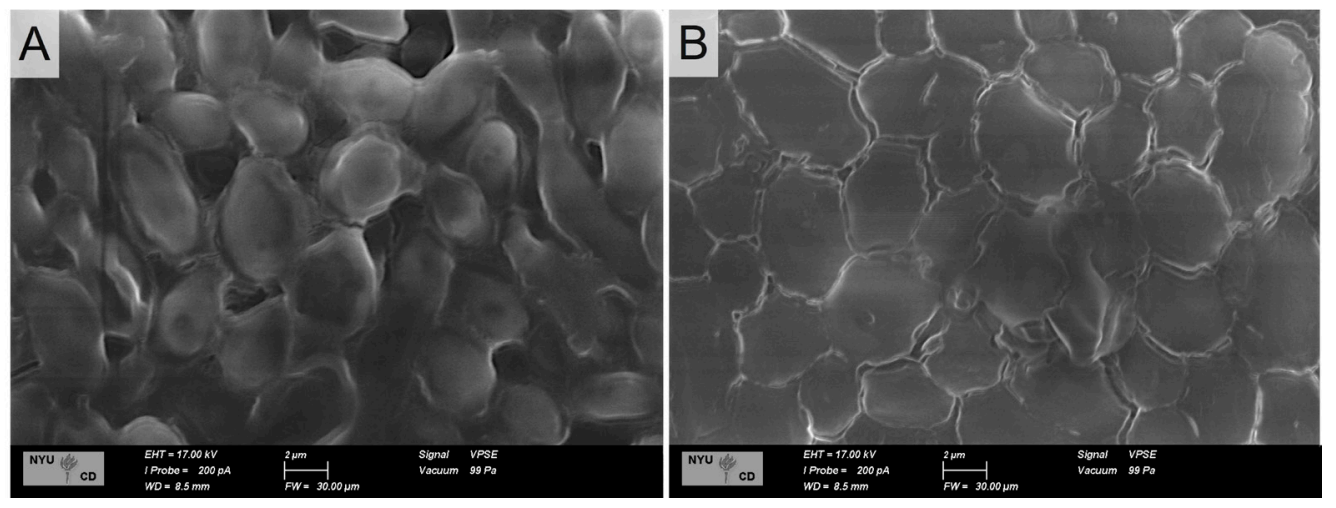

FIG. 7: (a) Biofilm not exposed to low-temperature plasma (LTP) treatment. (b) Cell damage after LTP treatment 
In addition, the reactive oxygen species (ozone, atomic oxygen, superoxide, peroxide, hydroxyl radicals, and nitric oxide) produced by plasma react with cellular biomacromolecules, including DNA, lipids, and proteins. ${ }^{10}$ The electrostatic forces generated by plasma-charged particles may also result in membrane lysis. ${ }^{37}$

The $C$. albicans cell wall is composed of mannoproteins (about $40 \%$ of the cell wall biomass), $\beta$-1,3-glucan (the major stress-bearing polysaccharide in the wall), $\beta$-1,6-glucan (a water-soluble component that interconnects mannoproteins to $\beta$-1,3-glucan), and chitin (a linear stress-bearing polysaccharide). ${ }^{14}$ Therefore, these major components are easy targets for the reactive species produced by LTP.

Koban et al. ${ }^{2}$ also stated that disinfection with plasma is based on short-lived active species, UV radiation, electrostatic effects, and reactive oxygen species that cause lipid peroxidation. According to Stoffels et al. ${ }^{21}$ and Pappas, ${ }^{23}$ even when no significant UV emission is present with low-temperature, atmospheric-pressure plasmas, the synergy of other species such as radicals and charged particles still plays a dominant role in the sterilization process.

The assumption about membrane damage caused by plasma was confirmed by the confocal and VPSEM images, revealing cell lyses (Figs. 5-7). Membrane perforation was previously reported; plasma reactive particles produce a general mechanical effect on the surface of living organisms called "etching." $33,36,38,39$ Etching results from the reaction of highly reactive gas radicals with organic materials, generating by-products that are desorbed from the surface. ${ }^{33}$ For both plasma tip-to-sample distances, however, the effect was limited to the center of the disc submitted to the LTP treatment. A similar trend was observed by Koban et al., ${ }^{2}$ revealing that the narrow plasma afterglow damages only yeast cells at the actual touch point, and the reactive plasma species do not spread over the entire disc in a sufficient dose. Therefore, additional studies of treatment all over the disc are suggested.

Although it has been suggested that plasma does not induce bulk modifications on materials, ${ }^{19,24,25}$ additional studies are being conducted to assess the effect of plasma on the mechanical and physicochemical properties of PMMA samples at different scenarios (exposure time, plasma tip-to-sample distance, gas composition, and so on).

It is important to highlight that $C$. albicans frequently adheres not only to denture surfaces ${ }^{14}$ but also to other medical devices, such as voice prostheses, ${ }^{40,41}$ blood and urinary catheters, ${ }^{42}$ and heart valves. ${ }^{43}$ Therefore, although the applicability of this approach requires more extensive studies, LTP has a broader scope and relevance for antimicrobial treatment.

\section{CONCLUSION}

A short period of LTP exposure (60 seconds) demonstrated an antifungal effect on $C$. albicans biofilm formed on PMMA, thus accepting the research hypothesis. LTP is a promising treatment for C. albicans biofilm-related diseases. 


\section{ACKNOWLEDGEMENTS}

The authors acknowledge the Department of Basic Science and Craniofacial Biology and Department of Biomaterials and Biomimetics of New York University College of Dentistry. They would also like to acknowledge the 2012 IADR/GSK Innovation in Oral Care Award for financial support

\section{REFERENCES}

1. de Freitas Fernandes FS, Pereira-Cenci T, da Silva WJ, Filho AP, Straioto FG, Del Bel Cury AA. Efficacy of denture cleansers on Candida spp. biofilm formed on polyamide and polymethyl methacrylate resins. J Prosthet Dent. 2011;105(1):51-8.

2. Koban I, Matthes R, Hubner NO, Welk A, Meisel P, Holtfreter B, Sietmann R, Kindel E, Weltmann KD, Kramer A, Kocher T. Treatment of Candida albicans biofilms with low-temperature plasma induced by dielectric barrier discharge and atmospheric pressure plasma jet. New J Phys. 2010;12:073039.

3. Budtz-Jorgensen E. The significance of Candida albicans in denture stomatitis. Scand J Dent Res. 1974;82(2):151-90.

4. Barbeau J, Seguin J, Goulet JP, de Koninck L, Avon SL, Lalonde B, Rompre P, Deslauriers N. Reassessing the presence of Candida albicans in denture-related stomatitis. Oral Surg Oral Med Oral Pathol Oral Radiol Endod. 2003;95(1):51-9.

5. Pereira-Cenci T, Del Bel Cury AA, Crielaard W, Ten Cate JM. Development of Candida-associated dentureí stomatitis: new insights. J Appl Oral Sci. 2008;16(2):86-94.

6. Yildirim MS, Hasanreisoglu U, Hasirci N, Sultan N. Adherence of Candida albicans to glow-discharge modified acrylic denture base polymers. J Oral Rehabil. 2005;32(7):518-25.

7. Chaffin WL, López-Ribot JL, Casanova M, Gozalbo D, Martínez JP. Cell wall and secreted proteins of Candida albicans: identification, function, and expression. Microbiol Mol Biol Rev. 1998;62(1):13080 .

8. Chandra J, Mukherjee PK, Leidich SD, Faddoul FF, Hoyer LL, Douglas LJ, Ghannoum MA. Antifungal resistance of candidal biofilms formed on denture acrylic in vitro. J Dent Res. 2001;80(3):903-8.

9. Sutherland IW. Exopolysaccharides in biofilms, flocs and related structures. Water Sci Technol. 2001;43(6):77-86.

10. Alkawareek MY, Algwari QT, Gorman SP, Graham WG, O'Connell D, Gilmore BF. Application of atmospheric pressure nonthermal plasma for the in vitro eradication of bacterial biofilms. FEMS Immunol Med Microbiol. 2012;65(2):381-4.

11. Nakamoto K, Tamamoto M, Hamada T. Evaluation of denture cleansers with and without enzymes against Candida albicans. J Prosthet Dent. 1991;66(6):792-5.

12. Verran J, Maryan CJ. Retention of Candida albicans on acrylic resin and silicone of different surface topography. J Prosthet Dent. 1997;77(5):535-9.

13. Nikawa H, Yamamoto T, Hamada T, Rahardjo MB, Murata H, Nakanoda S. Antifungal effect of zeolite-incorporated tissue conditioner against Candida albicans growth and/or acid production. J Oral Rehabil. 1997;24(5):350-7.

14. ten Cate JM, Klis FM, Pereira-Cenci T, Crielaard W, de Groot PW. Molecular and cellular mechanisms that lead to Candida biofilm formation. J Dent Res. 2009;88(2):105-15.

15. Sladek REJ, Stoffels E. Deactivation of Escherichia coli by the plasma needle. J Phys D Appl Phys. 2005;38(11):1716-21.

16. Dobrynin D, Fridman G, Friedman G, Fridman A. Physical and biological mechanisms of direct plasma interaction with living tissue. New J Phys. 2009;11:115020.

17. Sakiyama Y, Graves DB. Finite element analysis of an atmospheric pressure RF-excited plasma needle. J Phys D Appl Phys. 2006;39(16):3451-6. 
18. Stoffels E. Gas plasmas in biology and medicine. J Phys D Appl Phys. 2006;39(16).

19. Zamperini CA, Machado AL, Vergani CE, Pavarina AC, Giampaolo ET, da Cruz NC. Adherence in vitro of Candida albicans to plasma treated acrylic resin. Effect of plasma parameters, surface roughness and salivary pellicle. Arch Oral Biol. 2010;55(10):763-70.

20. Brun P, Brun P, Vono M, Venier P, Tarricone E, Deligianni V, Martines E, Zuin M, Spagnolo S, Cavazzana R, Cardin R, Castagliuolo I, Valerio Al, Leonardi A. Disinfection of ocular cells and tissues by atmospheric-pressure cold plasma. PloS One. 2012;7(3):e33245.

21. Stoffels E, Sakiyama Y, Graves DB. Cold atmospheric plasma: charged species and their interactions with cells and tissues. IEEE Trans Plasma Sci. 2008;36(4):1441-57.

22. Goree J, Liu B, Drake D, Stoffels E. Killing of S-mutans bacteria using a plasma needle at atmospheric pressure. IEEE Trans Plasma Sci. 2006;34(4):1317-24.

23. Pappas D. Status and potential of atmospheric plasma processing of materials. J Vac Sci Technol A. 2011;29(2):020801.

24. Hodak SK, Supasai T, Paosawatyanyong B, Kamlangkla K, Pavarajarn V. Enhancement of the hydrophobicity of silk fabrics by SF(6) plasma. Appl Surf Sci. 2008;254(15):4744-9.

25. Rangel EC, Gadioli GZ, Cruz NC. Investigations on the stability of plasma modified silicone surfaces. Plasma Polym. 2004;9(1):35-48.

26. Moura JS, da Silva WJ, Pereira T, Del Bel Cury AA, Rodrigues Garcia RC. Influence of acrylic resin polymerization methods and saliva on the adherence of four Candida species. J Prosthet Dent. 2006;96(3):205-11.

27. Del Bel Cury AA, Rached RN, Ganzarolli SM. Microwave-cured acrylic resins and silicone-gypsum moulding technique. J Oral Rehabil. 2001;28(5):433-8.

28. Luo G, Samaranayake LP. Candida glabrata, an emerging fungal pathogen, exhibits superior relative cell surface hydrophobicity and adhesion to denture acrylic surfaces compared with Candida albicans. APMIS. 2002;110(9):601-10.

29. Fridman G, Brooks AD, Balasubramanian M, Fridman A, Gutsol A, Vasilets VN, Ayan H, Friedman G. Comparison of direct and indirect effects of non-thermal atmospheric-pressure plasma on bacteria. Plasma Process Polym. 2007;4(4):370-5.

30. Kolb JF, Mohamed AAH, Price RO, Swanson RJ, Bowman A, Chiavarini RL, Stacey M, Schoenbach KH. Cold atmospheric pressure air plasma jet for medical applications. Appl Phys Lett. 2008;92(24):241501.

31. von Woedtke T, Kramer A, Weltmann KD. Plasma sterilization: what are the conditions to meet this claim? Plasma Process Polym. 2008;5(6):534-9.

32. Hawser SP, Douglas LJ. Resistance of Candida albicans biofilms to antifungal agents in vitro. Antimicrob Agents Chemother. 1995;39(9):2128-31.

33. Ermolaeva SA, Varfolomeev AF, Chernukha MY, Yurov DS, Vasiliev MM, Kaminskaya AA, Moisenovich MM, Romanova JM, Murashev AN, Selezneva II, Shimizu T, Sysolyatina EV, Shaginyan IA, Petrov OF, Mayevsky EI, Fortov VE, Morfill GE, Naroditsky BS, Gintsburg AL. Bactericidal effects of non-thermal argon plasma in vitro, in biofilms and in the animal model of infected wounds. J Med Microbiol. 2011;60(Pt 1):75-83.

34. Schlagenhauf U, Horlacher V, Netuschil L, Brecx M. Repeated subgingival oxygen irrigations in untreated periodontal patients. J Clin Periodontol. 1994;21(1):48-50.

35. Takenaka S, Iwaku M, Hoshino E. Artificial Pseudomonas aeruginosa biofilms and confocal laser scanning microscopic analysis. J Infect Chemother. 2001;7(2):87-93.

36. Moisan M, Barbeau J, Moreau S, Pelletier J, Tabrizian M, Yahia LH. Low-temperature sterilization using gas plasmas: a review of the experiments and an analysis of the inactivation mechanisms. Int $\mathrm{J}$ Pharm. 2001;226(1-2):1-21.

37. Boudam MK, Moisan M, Saoudi B, Popovici C, Gherardi N, Massines F. Bacterial spore inactivation by atmospheric-pressure plasmas in the presence or absence of UV photons as obtained with the same gas mixture. J Phys D Appl Phys. 2006;39(16):3494-507. 
38. Lerouge S, Guignot C, Tabrizian M, Ferrier D, Yagoubi N, Yahia L. Plasma-based sterilization: effect on surface and bulk properties and hydrolytic stability of reprocessed polyurethane electrophysiology catheters. J Biomed Mater Res. 2000;52(4):774-82.

39. Moreau M, Feuilloley MG, Veron W, Meylheuc T, Chevalier S, Brisset JL, Orange N. Gliding arc discharge in the potato pathogen Erwinia carotovora subsp. atroseptica: mechanism of lethal action and effect on membrane-associated molecules. Appl Environ Microbiol. 2007;73(18):5904-10.

40. Holmes AR, Gopal PK, Jenkinson HF. Adherence of Candida albicans to a cell-surface polysaccharide receptor on Streptococcus gordonii. Infect Immun. 1995;63(5):1827-34.

41. Holmes AR, van der Wielen P, Cannon RD, Ruske D, Dawes P. Candida albicans binds to saliva proteins selectively adsorbed to silicone. Oral Surg Oral Med Oral Pathol Oral Radiol Endod. 2006;102(4):488-94.

42. Jain N, Kohli R, Cook E, Gialanella P, Chang T, Fries BC. Biofilm formation by and antifungal susceptibility of Candida isolates from urine. Appl Environ Microb. 2007;73(6):1697-703.

43. Salamon SA, Fuursted K, Egeblad H, Petersen E, Ott P. Candida albicans tricuspid and pulmonic valve endocarditis: challenge of relapsing risk and role of combined medical treatment and surgery. Scand J Infect Dis. 2007;39(6-7):641-4. 